\title{
Controlling feeding practices and maternal migrant background: an analysis of a multicultural sample
}

Maria Somaraki ${ }^{1}$, Karin Eli ${ }^{2}$, Anna $\mathrm{Ek}^{3}$, Louise Lindberg ${ }^{3}$, Jonna $\mathrm{Nyman}^{3}$, Claude Marcus $^{3}$, Carl-Erik Flodmark ${ }^{4}$, Angelo Pietrobelli ${ }^{5}$, Myles S Faith ${ }^{6}$, Kimmo Sorjonen $^{7}$ and Paulina Nowicka ${ }^{1,3, *}$

${ }^{1}$ Department of Food, Nutrition and Dietetics, Uppsala University, Box 560, 75122 Uppsala, Sweden: ${ }^{2}$ Unit for Biocultural Variation and Obesity, Institute of Social and Cultural Anthropology, University of Oxford, Oxford, UK: ${ }^{3}$ Division of Pediatrics, Department of Clinical Science, Intervention and Technology, Karolinska Institutet, Stockholm, Sweden: ${ }^{4}$ Childhood Obesity Unit, Skåne University Hospital, Malmö, Sweden: ${ }^{5}$ Pediatric Unit, Verona University Medical School, Verona, Italy: ${ }^{6}$ Department of Counseling, School, and Educational Psychology, Graduate School of Education, University of Buffalo, Buffalo, NY, USA: ${ }^{7}$ Division of Psychology, Department of Clinical Neuroscience, Karolinska Institutet, Solna, Sweden

Submitted 14 April 2016: Final revision received 5 September 2016: Accepted 16 September 2016: First published online 21 November 2016

\begin{abstract}
Objective: Parental feeding practices shape children's relationships with food and eating. Feeding is embedded socioculturally in values and attitudes related to food and parenting. However, few studies have examined associations between parental feeding practices and migrant background.

Design: Cross-sectional study. Parental feeding practices (restriction, pressure to eat, monitoring) were assessed using the Child Feeding Questionnaire. Differences were explored in four sub-samples grouped by maternal place of birth: Sweden, Nordic/Western Europe, Eastern/Southern Europe and countries outside Europe. Crude, partly and fully adjusted linear regression models were created. Potential confounding variables included child's age, gender and weight status, and mother's age, weight status, education and concern about child weight.

Setting: Malmö and Stockholm, Sweden.

Subjects: Mothers ( $n$ 1325, representing seventy-three countries; mean age 36.5 years; $28.1 \%$ of non-Swedish background; $30.7 \%$ with overweight/obesity; $62.8 \%$ with university education) of pre-school children (mean age 4.8 years; $50 \cdot 8 \%$ boys; $18 \cdot 6 \%$ with overweight/obesity).

Results: Non-Swedish-born mothers, whether European-born or non-Europeanborn, were more likely to use restriction. Swedish-born mothers and Nordic/ Western European-born mothers reported lower levels of pressure to eat compared with mothers born in Eastern/Southern Europe and mothers born outside Europe. Differences in monitoring were small. Among the potential confounding variables, child weight status and concern about child weight were highly influential. Concern about child weight accounted for some of the effect of maternal origin on restriction.

Conclusions: Non-European-born mothers were more concerned about children being overweight and more likely to report controlling feeding practices. Future research should examine acculturative and structural factors underlying differences in feeding.
\end{abstract}

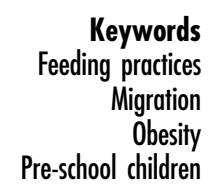

Overweight and obesity in childhood may lead to multiple adverse consequences that can impact a child's physical and psychosocial development ${ }^{(1)}$. The prevalence of overweight and obesity among children and adolescents has increased by about $40 \%$ in most Western countries between 1980 and $2013^{(2)}$. At the same time, a steeper increase, of about $60 \%$, has been observed in emerging economies $^{(2)}$. As a response to these rising rates, several studies have addressed the aetiology of childhood obesity, in order to inform early prevention strategies ${ }^{(3)}$. When exploring the aetiology of obesity much emphasis has been placed on the impact of environmental and 
behavioural changes ${ }^{(3-5)}$ that influence nutrition and physical activity ${ }^{(6)}$. Young children are highly dependent on their parents for food provision, and parental feeding practices may thus have a profound effect on children's eating behaviours and weight status ${ }^{(7-11)}$.

In Sweden, the prevalence of childhood obesity is about $4 \%$, compared with about $8 \%$ in Southern Europe; on the population level, childhood obesity is less pronounced in Sweden than in other Western and European countries ${ }^{(2)}$. Moreover, recent epidemiological studies have found that childhood obesity is stabilizing and leveling off in Sweden although the social gradient has become more evident $^{(12-14)}$. Weight disparities between children of Swedish background and children of first- or secondgeneration migrant background persist: in Sweden, children of Turkish, Iranian and South American background have up to three times higher odds of developing overweight or obesity ${ }^{(15,16)}$.

Most research studies on obesity-related parental feeding practices focus on three constructs: restriction, pressure to eat and monitoring ${ }^{(17,18)}$. High levels of restriction, characterized by a high degree of parental regulation of the types and amounts of food consumed by children, have been associated with children's increased eating in the absence of hunger, higher food responsiveness and lower responsiveness to satiety cues $^{(19-23)}$. High levels of pressure to eat, a construct that describes pushing a child to eat without prioritizing his or her internal satiety cues, have been related to fussiness, pickiness and limited interest in food, along with reduced appetite $^{(22,24-26)}$. Restriction and pressure to eat have been associated with children's weight status in numerous studies ${ }^{(27-31)}$, although a few studies have not found such associations $^{(25,32,33)}$. Monitoring is a construct characterized by keeping track of a child's food consumption. Although monitoring has been associated with lower food approach ${ }^{(22)}$, research on monitoring has been less extensive and less conclusive ${ }^{(34)}$.

Previous research has identified several correlates of parental feeding practices, including parents' perceptions of their children's weight status and concerns about their children being overweight or having abnormal appetite $^{(35-39)}$. Parental feeding practices are embedded in broader sociocultural contexts, reflecting social norms and culturally conditioned values and attitudes ${ }^{(40,41)}$. Feeding practices are thus influenced by perceptions of desirable weight status and body shape, which may vary substantially according to sociocultural norms ${ }^{(42)}$ and socio-economic status ${ }^{(43)}$. Experiences associated with socio-economic hardship, such as food insecurity, poverty and hunger, have also been linked to parental feeding practices $^{(44)}$.

Despite the important socio-economic and sociocultural dimensions of parental feeding practices, most studies of parental feeding have been conducted among largely ethnically homogeneous, middle-class Western populations ${ }^{(7)}$. Only a few studies (four in the USA and one in Germany and the UK), all with rather small samples, have focused on differences in controlling feeding practices among parents of different ethnic background; these studies found that controlling feeding practices are used less frequently among white US ${ }^{(45-48)}$ and white European parents ${ }^{(49)}$, compared with parents of minority ethnic background. Studies with larger samples, including parents from migrant backgrounds, are needed in order to understand associations between feeding practices and parental ethnic, cultural and national backgrounds, and thereby inform contemporary public health efforts in Europe.

The aim of the present study was to investigate associations between maternal country of birth and feeding practices in a large multicultural sample in Sweden. Specifically, the study examined associations between maternal origin and self-reported restriction, pressure to eat and monitoring practices, and assessed the influence of child and maternal characteristics as potentially relevant confounders. Based on research conducted in comparable European settings, we hypothesized that mothers born outside Sweden are more likely to engage in controlling feeding practices ${ }^{(49)}$.

\section{Methods}

\section{Setting, participants and data collection}

The total sample included 1325 mothers of children aged 4 to 7 years. Data were collected through the Child Feeding Questionnaire (CFQ) ${ }^{(17)}$ and a background questionnaire, which included questions regarding sociodemographic and anthropometric characteristics of children and mothers; all distributed questionnaires were in Swedish. Participants were recruited through three groupings: a population-based sample in Malmö, a school-based sample in Stockholm and a clinically based sample in Stockholm. In all three groupings, responses were collected by mail. In Malmö, the Swedish Population Registry was used to recruit mothers; 876 out of the total of 3007 mothers of 4-year-olds participated in the study (response rate $29 \%)^{(50)}$. In Stockholm, the school-based sample targeted five schools and twenty pre-schools from areas with low, medium and high prevalence of obesity (compared with rates in Stockholm county); 432 out of 931 parents participated (response rate $46 \%)^{(35,51)}$. In the present study we used only data provided by mothers (n 351 in total). We added a clinically based sample in order to identify differences between parents of overweight or obese children and parents of normal-weight children. This sample consisted of baseline data from mothers of ninety-eight children with obesity aged 4 to 6 years. The children were referred by primary health-care centres across the county to an ongoing randomized controlled childhood obesity trial (NCT01792531) ${ }^{(52)}$. 
The response rate was $87.5 \%$. The recruitment process and data collection procedures have been described in detail elsewhere for the Malmö sample ${ }^{(50)}$ and for the Stockholm samples ${ }^{(35,51,52)}$.

\section{Parental feeding practices}

CFQ is an established, self-administered, seven-factor questionnaire assessing parental feeding practices, beliefs and attitudes related to obesity proneness among children and adolescents ${ }^{(17)}$. The Swedish version of CFQ has been validated using confirmatory factor analysis and an optimal fit was obtained after excluding two questions regarding parental reward ${ }^{(50)}$. Restriction, pressure to eat and monitoring are all CFQ factors. Restriction (Cronbach's $\alpha=0 \cdot 81$ ) was measured by six items:

1. 'I have to be sure that my child does not eat too many sweets (candy, ice cream, cake or pastries)';

2. 'I have to be sure that my child does not eat too many high-fat foods';

3. 'I have to be sure that my child does not eat too much of his/her favourite foods';

4. 'I intentionally keep some foods out of my child's reach';

5. 'If I did not guide or regulate my child's eating, he/she would eat too many junk foods'; and

6. 'If I did not guide or regulate my child's eating, he/she would eat too much of his/her favourite foods'.

The response options were scored: 1='disagree', $2=$ 'slightly disagree', $3=$ 'neutral', $4=$ 'slightly agree', $5=$ 'agree'.

Pressure to eat (Cronbach's $\alpha=0.69$ ) was measured by four items:

1. 'My child should always eat all of the food on his/her plate';

2. 'I have to be especially careful to make sure my child eats enough';

3. "If my child says "I am not hungry", I try to get him/her to eat anyway'; and

4. 'If I did not guide or regulate my child's eating, he/she would eat much less than he/she should'.

The response options were scored: $1=$ 'disagree', $2=$ 'slightly disagree', $3=$ 'neutral', $4=$ 'slightly agree', $5=$ 'agree'.

Monitoring (Cronbach's $\alpha=0 \cdot 77$ ) was measured by three items:

1. 'How much do you keep track of the sweets (candy, ice cream, cake, pies, pastries) that your child eats?';

2. 'How much do you keep track of the snack food (potato chips, Doritos, cheese puffs) that your child eats?'; and

3. 'How much do you keep track of the high-fat foods that your child eats?'.

The response options were scored: $1=$ 'never', $2=$ 'rarely', $3=$ 'sometimes', $4=$ 'mostly', $5=$ 'always'.
Another CFQ factor is concern about child weight; in the present study, concern about child weight (Cronbach's $\alpha=0.86$ ) was examined as a potential confounder. It consisted of three items:

1. 'How concerned are you about your child eating too much when you are not around him/her?';

2. 'How concerned are you about your child having to diet to maintain a desirable weight?; and

3. 'How concerned are you about your child becoming overweight?'.

The responses options were: 1 = 'unconcerned', 2 = 'a little concerned', 3 ='concerned', $4=$ 'fairly concerned', $5=$ 'very concerned'.

Mean scores for each subscale were calculated; for each practice, higher scores represented more frequent use.

\section{Background characteristics}

A sociodemographic and anthropometric questionnaire was designed using items from established instruments. Data were collected on children's age (in years), gender (boy or girl), height (in centimetres) and weight (in kilograms), and on mothers' age (in years), height (in centimetres), weight (in kilograms) and level of education (more than 12 years or less than 12 years). Mother's country of birth was self-reported in the background questionnaire based on the question 'In which country were you born?', with two answer options: 'I was born in: (i) Sweden, (ii) another country, please specify'.

BMI $\left(\mathrm{kg} / \mathrm{m}^{2}\right)$ was calculated for children and their mothers, and was then used to establish the categories of overweight/obese and normal weight. The mothers' weights and heights were self-reported in all samples. The children's weights and heights were self-reported in the population-based non-clinical samples and measured by trained health-care professionals in the clinical sample. Child weight categories were created using age- and gender-specific international cut-offs for $\mathrm{BMI}^{(53)}$.

\section{Data analyses}

Descriptive statistics are presented as means (for continuous variables) and percentages (for categorical variables). Taking into consideration the large sample size ( $n$ 1325) and implications of the central limit theorem for normality in larger sample sizes, parametric tests were chosen. One-way ANOVA and $\chi^{2}$ analyses were performed in order to explore possible differences in continuous and categorical variables across the groups established through mother's place of birth. Once statistical significance was attained through ANOVA, post hoc analyses were performed using Bonferroni tests for multiple comparisons, in order to identify differences in continuous variables across the groups based on mother's place of birth (these results are not reported in the present paper). Multiple linear regression was carried out, with restriction, pressure to eat and monitoring as dependent 
variables and mother's place of birth as the primary exposure variable, to test the crude (Model I), partly adjusted (for child weight, Model II; and for concern about child weight, Model III) and fully adjusted models (Model IV). Unstandardized regression coefficients (b) were interpreted as the difference in scores between the reference group (Swedish-born mothers) and each of the three categories (Nordic/Western European-born, Eastern/ Southern European-born and non-European-born). The confounders included child's age, gender and weight status and mother's age, weight status, level of education and concern about child weight. All $P$ values $<0.05$ were considered to be statistically significant. All analyses were performed using the statistical software package IBM SPSS Statistics Version 22.0.

\section{Results}

\section{Study population}

Table 1 provides an overview of the seventy-three countries, including Sweden, represented in the sample. Out of 1325 participating mothers, forty-one mothers did not indicate their country of origin and thus the total valid sample includes 1284 mothers. Of the mothers, 923 were born in Sweden, 159 were born in a European country other than Sweden and 202 were born outside Europe. No country of origin, except Sweden, was represented by more than $5 \%$ of the whole sample.

Mothers born in Europe were from thirty countries. The most represented European country was Denmark (thirty mothers), followed by Poland (twenty-one mothers). Mothers who were born outside Europe had origins in forty-two countries. The Middle East and North Africa region was the most represented, with 114 mothers from twelve countries, comprising $9 \%$ of the valid cases; fiftynine mothers were born in Iraq, which was the most represented country outside Europe.

Based on sociogeographic similarities and group size we created four sub-samples: (i) mothers born in Sweden ( $n$ 923); (ii) mothers born in a Nordic country or in Western Europe (including the USA and Australia, due to sociocultural similarities; $n$ 70); (iii) mothers born in Eastern or Southern Europe (including Russia; $n$ 93); and (iv) mothers born in the Middle East and North Africa, Asia, Latin America or sub-Saharan Africa, which we grouped under the heading of non-European-born ( $n$ 198).

Table 2 shows the descriptive characteristics of the total sample and of the four sub-samples. Significant differences were found between the four sub-samples in children's and mothers' weight status and mothers' education level. Mothers born in Sweden had a higher education level and lower levels of overweight and obesity in comparison with the mothers from the other three sub-samples. Swedishborn mothers reported the lowest level of concern about child weight, the lowest level of restriction and pressure to eat, and the highest level of monitoring practices, compared with mothers from the other three sub-samples.

\section{Parental feeding practices}

\section{Restriction}

Table 3 shows the results of the multiple linear regression analyses. Maternal origin was found to explain $9 \%$ of the variance in restriction for Model I, the crude model. In Model II (adjusted for child's weight status), the explained variance increased to $17 \%$. In Model III (adjusted for maternal concern), the explained variance increased to $25 \%$. In the fully adjusted model, the explained variance was $28 \%$. This indicates that child weight and maternal concern seem to be more important than mothers' characteristics, such as age, weight status and education, in influencing feeding practices. Among the studied variables, maternal concern about child weight was highly influential. The first two models showed similar patterns with regard to the effect of mother's country of birth (Nordic/Western European-born, Eastern/Southern European-born and non-European-born: $b=0 \cdot 40,0.70$ and 0.80 for the crude model and 0.37, 0.65 and 0.67 for the model adjusted for child's weight status, respectively). However, adjusting for concern resulted in a different pattern; this pattern remained consistent after adjusting for all other confounders $(b=0.37,0.47$ and 0.38 for the model adjusted for concern, and $0.35,0.43$ and 0.34 for the fully adjusted model, respectively). This indicates that concern about child weight accounts for some of the effect of maternal origin on restriction. For example, the difference in maternal concern can explain $52 \%((0 \cdot 80-0 \cdot 38) / 0 \cdot 80=0 \cdot 52)$ of the difference in restriction between Swedish-born and non-European-born mothers.

Moreover, in the fully adjusted model, weight status and the age of both the child and the mother were important. Child's $(b=0.27 ; 95 \%$ CI $0 \cdot 11,0.42)$ and mother's ( $b=0.13$; $95 \%$ CI $0 \cdot 01,0 \cdot 24$ ) weight status were positively associated, while child's ( $b=-0 \cdot 16 ; 95 \%$ CI $-0 \cdot 22,-0 \cdot 09)$ and mother's age $(b=-0.01 ; 95 \%$ CI $-0.02,-0.001)$ were negatively associated with restriction.

\section{Pressure to eat}

Maternal origin explained $3.6 \%$ of the variance in the use of pressure to eat (Table 3). The explained variance increased to $6.5 \%$ when adjusting for child's weight status. Adjusting for concern yielded the same explained variance of $6.5 \%$. In the fully adjusted model, the variance increased to $8.2 \%$. In contrast, for pressure to eat, the effect of mother's country of birth showed a consistent pattern, with Swedish- and Nordic/ Western European-born mothers demonstrating the lowest values and non-European-born mothers demonstrating the highest values. In all models, no significant differences were observed between Swedish-born mothers and Nordic/Western European-born mothers with regard to pressure to eat. Mothers born in Eastern/Southern Europe had higher scores on pressure to eat, and non-European-born mothers had the 
Table 1 Mothers' reported countries of origin, grouped by sociogeographic similarities, in the sample of mothers ( $n$ 1325) of children aged 4-7 years, Malmö and Stockholm, Sweden

\begin{tabular}{|c|c|c|c|}
\hline Country of origin & $n$ & Country of origin & $n$ \\
\hline Swedish, total & 923 & Non-European, total & 198 \\
\hline $\begin{array}{l}\text { Nordic, other than Sweden, total } \\
\text { 1. Denmark }\end{array}$ & $\begin{array}{l}53 \\
30\end{array}$ & $\begin{array}{l}\text { Middle East and North Africa, total } \\
\text { 1. Iraq (including Kurdistan/Iraq, } n \text { ) }\end{array}$ & $\begin{array}{r}114 \\
59\end{array}$ \\
\hline 2. Finland & 18 & 2. Iran & 17 \\
\hline 3. Norway & 3 & 3. Jordan & 2 \\
\hline \multirow[t]{2}{*}{ 4. Iceland } & \multirow[t]{2}{*}{2} & 4. Kuwait & 1 \\
\hline & & 5. Lebanon & 20 \\
\hline Western Europe, total & 13 & 6. Morocco & 1 \\
\hline 1. Belgium & 2 & 7. Libya & 2 \\
\hline 2. Great Britain & 2 & 8. Palestinian Territories/Palestine & 1 \\
\hline 3. France & 2 & 9. Sudan & 1 \\
\hline 4. The Netherlands & 1 & 10. Syria & 3 \\
\hline 5. Austria & 1 & 11. Turkey & 6 \\
\hline 6. Germany & 5 & 12. United Arab Emirates & 1 \\
\hline Eastern Europe and the Balkans, total & 87 & East, South and South-East Asia, total & 50 \\
\hline 1. Estonia & 3 & 1. Afghanistan & 10 \\
\hline 2. Kosovo & 8 & 2. Bangladesh & 1 \\
\hline 3. Croatia & 3 & 3. Cambodia & 2 \\
\hline 4. Lithuania & 3 & 4. China & 7 \\
\hline 5. FYROM/Macedonia & 7 & 5. Japan & 3 \\
\hline 6. Moldova & 1 & 6. South Korea & 6 \\
\hline 7. Montenegro & 1 & 7. Pakistan & 4 \\
\hline 8. Poland & 21 & 8. The Philippines & 3 \\
\hline 9. Romania & 5 & 9. Sri Lanka & 2 \\
\hline 10. Russia & 4 & 10. Taiwan & 1 \\
\hline 11. Serbia & 6 & 11. Thailand & 5 \\
\hline 12. Slovakia & 1 & 12. Vietnam & 6 \\
\hline 13. Czech Republic & 3 & & \\
\hline 14. Ukraine & 2 & Sub-Saharan Africa, total & 15 \\
\hline 15. The former Yugoslavia & 1 & 1. Congo & 2 \\
\hline 16. Bosnia & 17 & 2. Eritrea & 1 \\
\hline \multirow[t]{2}{*}{ 17. Bulgaria } & \multirow[t]{2}{*}{1} & 3. Ethiopia & 3 \\
\hline & & 4. Gambia & 1 \\
\hline Southern Europe, total & 6 & 5. Ghana & 1 \\
\hline 1. Greece & 1 & 6. Ivory Coast & 1 \\
\hline 2. Italy & 4 & 7. Somalia & 4 \\
\hline \multirow[t]{13}{*}{ 3. Spain } & \multirow[t]{13}{*}{1} & 8. Tanzania & 1 \\
\hline & & 9. Uganda & 1 \\
\hline & & Central and South America, total & 19 \\
\hline & & 1. Argentina & 2 \\
\hline & & 2. Bolivia & 1 \\
\hline & & 3. Brazil & 1 \\
\hline & & 4. Chile & 10 \\
\hline & & 5. Ecuador & 2 \\
\hline & & 6. Guatemala & 1 \\
\hline & & 7. Honduras & 2 \\
\hline & & Other, total & 4 \\
\hline & & 1. Australia† & 1 \\
\hline & & 2. USA† & 3 \\
\hline
\end{tabular}

Country of origin not reported: $n 41$.

†Included in the 'Nordic/Western European' group due to sociocultural similarities.

highest scores. As in the case of restrictive feeding practices, child weight status and maternal concern about child weight were most influential. In the fully adjusted model, child's weight status $(b=-0 \cdot 30 ; 95 \% \mathrm{CI}-0 \cdot 46,-0 \cdot 13)$ was negatively associated with pressure to eat, as was maternal concern about child weight $(b=-0 \cdot 14 ; 95 \%$ CI $-0 \cdot 22,-0 \cdot 06)$.
Maternal age, education and BMI had weak associations with pressure to eat in Model IV.

\section{Monitoring}

In comparison with restriction and pressure to eat, the explained variance in monitoring was much lower in 
Table 2 Descriptive statistics of the study population of mothers $(n 1325)$ of children aged $4-7$ years, Malmö and Stockholm, Sweden

\begin{tabular}{|c|c|c|c|c|c|c|}
\hline & $\begin{array}{l}\text { Total population } \\
\quad(n 1325)\end{array}$ & $\begin{array}{l}\text { Sweden } \\
(n \text { 923) }\end{array}$ & $\begin{array}{c}\text { Nordic country/ } \\
\text { Western Europe } \\
(n 70) \\
\end{array}$ & $\begin{array}{c}\text { Eastern and } \\
\text { Southern Europe } \\
(n \text { 93) } \\
\end{array}$ & $\begin{array}{c}\text { Non-European } \\
\text { country } \\
(n \text { 198) }\end{array}$ & \\
\hline & Mean or \% & Mean or $\%$ & Mean or $\%$ & Mean or $\%$ & Mean or $\%$ & $P$ value \\
\hline Child's gender (\%) & & & & & & $0.563 \dagger$ \\
\hline Boy & $50 \cdot 8$ & $50 \cdot 1$ & $47 \cdot 1$ & $48 \cdot 4$ & 54.9 & \\
\hline Girl & $49 \cdot 2$ & 49.9 & 52.9 & $51 \cdot 6$ & $45 \cdot 1$ & \\
\hline Child's age (years), mean & 4.80 & 4.85 & 4.76 & 4.60 & 4.63 & $<0.001 \ddagger$ \\
\hline Child's weight status (\%) & & & & & & $<0.001 \dagger$ \\
\hline Not overweight or obese & $81 \cdot 4$ & $85 \cdot 3$ & $81 \cdot 8$ & $78 \cdot 3$ & $68 \cdot 9$ & \\
\hline Overweight or obese & $18 \cdot 6$ & $14 \cdot 7$ & $18 \cdot 2$ & $21 \cdot 7$ & $31 \cdot 1$ & \\
\hline Mother's age (years), mean & $36 \cdot 5$ & $37 \cdot 0$ & $36 \cdot 5$ & 33.6 & $35 \cdot 2$ & $<0.001 \ddagger$ \\
\hline Mother's weight status (\%) & & & & & & $<0.001 \dagger$ \\
\hline Not overweight or obese & $69 \cdot 3$ & $72 \cdot 1$ & $67 \cdot 2$ & $69 \cdot 6$ & $55 \cdot 3$ & \\
\hline Overweight or obese & $30 \cdot 7$ & $27 \cdot 9$ & $32 \cdot 8$ & $30 \cdot 4$ & 44.7 & \\
\hline Mother's education (\%) & & & & & & $<0.001 \dagger$ \\
\hline 12 years or fewer & $37 \cdot 2$ & $29 \cdot 8$ & $32 \cdot 9$ & $60 \cdot 2$ & 63.6 & \\
\hline More than 12 years & $62 \cdot 8$ & $70 \cdot 2$ & $67 \cdot 1$ & 39.8 & $36 \cdot 4$ & \\
\hline CFQ Concern, mean & 1.48 & $1 \cdot 30$ & 1.33 & 1.79 & $2 \cdot 25$ & $<0.001 \ddagger$ \\
\hline CFQ Restriction, mean & $2 \cdot 63$ & 2.44 & $2 \cdot 86$ & $3 \cdot 13$ & 3.25 & $<0.001 \ddagger$ \\
\hline CFQ Pressure to eat, mean & $2 \cdot 81$ & $2 \cdot 70$ & $2 \cdot 73$ & $3 \cdot 11$ & 3.24 & $<0.001 \ddagger$ \\
\hline CFQ Monitoring, mean & $3 \cdot 86$ & 3.91 & $3 \cdot 89$ & 3.80 & 3.63 & $0.001 \ddagger$ \\
\hline
\end{tabular}

CFQ, Child Feeding Questionnaire.

$P$ value: significance level is 0.05 .

Includes $n 41$ where country of origin was not reported.

tChi-square test for categorical variables.

fOne-way ANOVA for continuous variables.

all models. The explained variance reached $1.3 \%$ in the fully adjusted model (Table 3). Non-European-born mothers scored significantly lower in monitoring compared with Swedish-born mothers in all models. In Model II (adjusted for child's weight status), child's weight status was positively associated with use of monitoring ( $b=0 \cdot 20 ; 95 \%$ CI $0 \cdot 06$, 0.34). In Model III (adjusted for maternal concern), concern was also positively associated with use of monitoring ( $b=0.09 ; 95 \%$ CI 0.03, 0.15); however, neither of these two confounders was significantly associated with monitoring in the fully adjusted model. Child's gender and maternal education were not associated with monitoring.

\section{Discussion}

The present study is the first to investigate differences in controlling feeding practices between Swedish-born and non-Swedish-born mothers. The study accounted for potential confounding variables, including mother's education and weight status, child's gender and weight status and mother's concern about child weight, while examining potential associations between mother's region of origin - as defined through groupings by country of birth - and feeding practices. The analysis found significant associations between mothers' migrant backgrounds and their feeding practices. Specifically, the analysis found that nonSwedish-born mothers, whether European-born or nonEuropean-born, were more likely to report using restriction. In contrast, Swedish-born mothers and Nordic/Western
European-born mothers reported similar levels of pressure to eat; these levels were lower in comparison with mothers born in Eastern/Southern Europe and mothers born outside Europe. Among the potential confounding variables, child's weight status and concern about child weight were the most influential. Specifically, maternal concern about child weight accounts for some of the effect of maternal origin on restriction.

Compared with restriction and pressure to eat, the analyses showed much smaller differences between the groups regarding monitoring. In all four groups, most mothers scored higher on monitoring than on the other two practices, possibly reflecting the social desirability of endorsing monitoring practices. This ceiling effect made it difficult to examine associations between maternal background and monitoring, due to the limited variance of the results. Thus, the remainder of the discussion focuses on the analysis of relationships between maternal background, restriction and pressure to eat.

The current study extends the growing body of research on parental feeding practices by linking feeding practices and maternal migrant backgrounds. Only one other European study explored feeding in a multicultural context $^{(49)}$. The study, which involved British and German mothers of children aged 2-12 years, found that German participants of Afro-Caribbean origin used restrictive feeding practices more often and monitoring less often than white German-born and UK-born participants. In another multicultural context, a US study showed that restrictive feeding was higher among Hispanic mothers of pre-school children, 
Table 3 Crude and adjusted unstandardized regression effects ( $b$; with $95 \%$ confidence intervals) when predicting feeding practices from children's and mothers' characteristics in the total sample of mothers ( $n$ 1325) of children aged 4-7 years, Malmö and Stockholm, Sweden

\begin{tabular}{|c|c|c|c|c|c|c|}
\hline \multirow[b]{2}{*}{ Model/predictor } & \multicolumn{2}{|c|}{ Restriction } & \multicolumn{2}{|c|}{ Pressure to eat } & \multicolumn{2}{|c|}{ Monitoring } \\
\hline & $b$ & $95 \% \mathrm{Cl}$ & $b$ & $95 \% \mathrm{Cl}$ & $b$ & $95 \% \mathrm{Cl}$ \\
\hline Model I & \multicolumn{2}{|c|}{ Adj. $R^{2}=0.092$} & \multicolumn{2}{|c|}{ Adj. $R^{2}=0.036$} & \multicolumn{2}{|c|}{ Adj. $R^{2}=0.003$} \\
\hline Nordic/Western European† & $0.40^{*}$ & $0.15,0.64$ & -0.03 & $-0.28,0.21$ & 0.03 & $-0.2,0.26$ \\
\hline Eastern/Southern European $\dagger$ & $0.70^{\star \star}$ & $0.47,0.93$ & $0.40^{\star \star}$ & $0.18,0.63$ & -0.03 & $-0.24,0.18$ \\
\hline Non-Europeant & $0.80^{\star \star}$ & $0.62,0.97$ & $0.50^{\star \star}$ & $0.33,0.67$ & $-0 \cdot 20^{\star}$ & $-0.36,-0.04$ \\
\hline Model II & \multicolumn{2}{|c|}{ Adj. $R^{2}=0.166$} & \multicolumn{2}{|c|}{ Adj. $R^{2}=0.065$} & \multicolumn{2}{|c|}{ Adj. $R^{2}=0.009$} \\
\hline Nordic/Western European† & $0.37^{\star}$ & $0.13,0.61$ & -0.02 & $-0.26,0.22$ & 0.02 & $-0.21,0.25$ \\
\hline Eastern/Southern European† & $0.65^{\star *}$ & $0.43,0.87$ & $0.43^{\star \star}$ & $0.21,0.65$ & -0.04 & $-0.25,0.17$ \\
\hline Non-European† & $0.67^{\star \star}$ & $0.50,0.84$ & $0.58^{\star \star}$ & $0.41,0.75$ & $-0.23^{\star}$ & $-0.4,-0.07$ \\
\hline Child’s overweight/obesity $\ddagger$ & $0 \cdot 72^{\star \star}$ & $0.57,0.86$ & $-0.44^{\star \star}$ & $-0.58,-0.29$ & $0.20^{*}$ & $0.06,0.34$ \\
\hline Model III & \multicolumn{2}{|c|}{ Adj. $R^{2}=0.250$} & \multicolumn{2}{|c|}{ Adj. $R^{2}=0.065$} & \multicolumn{2}{|c|}{ Adj. $R^{2}=0.009$} \\
\hline Nordic/Western European† & $0 \cdot 37^{*}$ & $0.15,0.60$ & -0.02 & $-0.27,0.22$ & 0.02 & $-0.21,0.25$ \\
\hline Eastern/Southern European $\dagger$ & $0.47^{\star \star}$ & $0.26,0.68$ & $0.50^{* *}$ & $0.27,0.72$ & -0.07 & $-0.28,0.14$ \\
\hline Non-European $\dagger$ & $0 \cdot 38^{\star *}$ & $0.22,0.55$ & $0.68^{\star \star}$ & $0.50,0.85$ & $-0.28^{\star}$ & $-0.44,-0.11$ \\
\hline CFQ Concern & $0.48^{\star \star}$ & $0.42,0.54$ & $-0 \cdot 20^{\star *}$ & $-0.27,-0.13$ & $0.09^{*}$ & $0.03,0.15$ \\
\hline Model IV & \multicolumn{2}{|c|}{ Adj. $R^{2}=0.280$} & \multicolumn{2}{|c|}{ Adj. $R^{2}=0.082$} & \multicolumn{2}{|c|}{ Adj. $R^{2}=0.013$} \\
\hline Nordic/Western European† & $0.35^{\star}$ & $0.13,0.57$ & -0.02 & $-0.26,0.22$ & 0.02 & $-0.21,0.24$ \\
\hline Eastern/Southern European† & $0.43^{\star \star}$ & $0.22,0.64$ & $0.40^{\star}$ & $0.17,0.63$ & -0.09 & $-0.31,0.12$ \\
\hline Non-European† & $0.34^{\star \star}$ & $0.17,0.50$ & $0.61^{\star *}$ & $0.43,0.79$ & $-0.28^{\star}$ & $-0.46,-0.11$ \\
\hline Child girl§ & 0.02 & $-0.08,0.12$ & 0.03 & $-0.08,0.14$ & 0.08 & $-0.02,0.18$ \\
\hline Child's age & $-0 \cdot 16^{\star \star}$ & $-0.22,-0.09$ & -0.04 & $-0.12,0.03$ & -0.03 & $-0.1,0.03$ \\
\hline Child’s overweight/obesity $\ddagger$ & $0.27^{\star}$ & $0.11,0.42$ & $-0 \cdot 30^{\star \star}$ & $-0.46,-0.13$ & 0.14 & $-0.02,0.3$ \\
\hline Mother's age & $-0.01^{*}$ & $-0.02,-0.001$ & $-0.01^{*}$ & $-0.03,-0.002$ & -0.01 & $-0.02,0.001$ \\
\hline Mother’s overweight/obesity $\ddagger$ & $0.13^{\star}$ & $0.01,0.24$ & -0.01 & $-0.13,0.11$ & 0.01 & $-0.1,0.13$ \\
\hline Mother's education > 12 years\|ll & 0.09 & $-0.02,0.21$ & $-0 \cdot 10$ & $-0.22,0.02$ & 0.03 & $-0.08,0.15$ \\
\hline CFQ Concern & $0.42^{\star *}$ & $0.35,0.50$ & $-0 \cdot 14^{\star \star}$ & $-0.22,-0.06$ & 0.06 & $-0.02,0.13$ \\
\hline
\end{tabular}

CFQ, Child Feeding Questionnaire.

Includes $n 41$ where country of origin was not reported.

${ }^{\star} P<0.05,{ }^{* \star} P<0.001$.

†Compared with Swedish-born mothers.

¥Compared with normal weight.

$\S$ Compared with male child.

॥Compared with $\leq 12$ years.

compared with non-Hispanic white mothers ${ }^{(47)}$. Another study based in the USA, with slightly older parents, also showed that Hispanic parents endorsed the highest levels of restriction and pressure to eat, while non-Hispanic white parents endorsed the lowest levels ${ }^{(45)}$. However, while the aforementioned studies focused on ethnicity as a variable, the present study is the first to examine associations between migrant background and feeding practices.

There are three possible reasons why non-Swedish-born mothers report higher use of controlling feeding practices. First, controlling feeding practices may reflect culturally conditioned modes of parental communication with children. In a cross-cultural study that compared US families of diverse ethnic backgrounds with Swedish families, clear differences were observed in the dynamics of play between parents and infants, with US families showing a much higher interaction tempo than Swedish families ${ }^{54)}$. Interestingly, the researchers observed that the US children were not overwhelmed by the higher tempo and that the Swedish children were not understimulated by the lower tempo. Similarly, the perception and reception of feeding practices may be culturally conditioned, and it is important to note that most studies where controlling feeding practices were found to be counterproductive were conducted among white US families, with negative influences particularly pronounced for girls ${ }^{(19)}$. In other studies, especially those conducted among Hispanic and African-American families, no link was observed between the level of controlling feeding practices and weight gain in children ${ }^{(46,55,56)}$. It is possible, then, that controlling feeding may not substantially disrupt children's self-regulation of appetite in an environment where controlling feeding practices are more common and have fewer negative connotations.

Another possible interpretation of the study's findings is that parents are more likely to employ controlling feeding practices when facing stressful situations. Studies have shown links between stress and feeding ${ }^{(57)}$, and between stress and childhood obesity ${ }^{(58)}$. Furthermore, in the related area of parental mental health, studies have found associations between parental depression or anxiety and feeding practices ${ }^{(57,59-63)}$. It is important to note that behavioural changes caused by depression and stress may differ ${ }^{(64)}$. Symptoms may vary considerably depending on the context and length of depressive or stressful periods. Because experiences of migration are associated with increased longterm stress ${ }^{(65,66)}$ and structural vulnerabilities, parents may be less able to be attentive to children's needs and may engage in pressuring or restrictive feeding practices as a result. The results of our recent analysis of associations between sense of coherence (a concept linked to resilience to stress), 
parental feeding practices, parental socio-economic status and parental migrant origin support this suggested nexus between migration, stress and controlling feeding ${ }^{(67)}$.

Possible regional differences in concern about child weight offer a further explanation of differences in parental feeding practices. Our results suggest that variations in controlling feeding practices are partly explained by differences in the weight status of children and, even more so, by maternal concern about child weight; notably, in the case of restriction, maternal concern overrides the effect of maternal origin. In our study, higher proportions of non-Swedish-born mothers reported concern over child weight. These results are in line with a 2013 study that analysed data from eight European countries and found that about half of parents in Southern Europe were concerned about their children's potential for unhealthy weight, in comparison with one-third of parents in Northern and Central Europe ${ }^{(42)}$. Of note, large proportions of parents, especially in Southern Europe, were concerned about their children's potential for both underweight and overweight. The authors argue that 'having both concerns may imply the presence of a more universal uneasiness, of which weight concerns may be just one part $^{{ }^{(42)}}$. Such regional differences may reflect both specific anxieties about eating, weight and the body, and anxieties born of economic inequality and uncertainty ${ }^{(68)}$. As the mothers of non-Swedish origin who participated in our study were able to complete the questionnaire in Swedish suggesting they had gone through some acculturative processes - it is also possible that increased maternal concern about child weight was accentuated by integrating into Swedish society, where emphasis is placed on lean body weight and appearance ${ }^{(69)}$.

The present study has several strengths and limitations. The study has a larger sample ( $n$ 1325) than previous studies that examined associations between parental national or ethnic background and controlling feeding practices. The large sample and the diversity of participants' birthplaces (a total of seventy-two countries, apart from Sweden), in combination with the use of a population registry, make the study particularly robust. Since detailed Swedish registers are widely accessible, the final sample was found to reflect demographic aspects measured on the regional level, with the exception of level of education ${ }^{(70)}$. The study's main limitation was the use of self-reports to determine BMI in the population-based and school samples. Cultural values affect the reporting of weight and height ${ }^{(71,72)}$, such that overestimation and underestimation are possible, especially for those children who have developed obesity ${ }^{(73,74)}$. Another limitation is lack of information about fathers' countries of birth, as there might be some differences between families with one parent of non-Swedish background and families with two parents of non-Swedish background. An additional limitation may have been posed by language: the questionnaires were in Swedish only, which may have affected the quality of responses provided by participants who were not fluent in Swedish, and may have influenced the sample as well. Furthermore, the use of a cross-sectional design did not allow us to analyse whether mothers of non-Swedish origin have changed their feeding practices after moving to Sweden as a result of their migration experience. Finally, the interpretation of the results was limited by the parameters set for comparison; in the analysis, the participants' countries of origin were grouped based on their geographic location (European and non-European) in most cases and sociocultural similarities in a few cases. The extent to which place of birth correlates with food and feeding practices can vary considerably between individuals, as well as between and within migrant groups, and it is likely that some nonSwedish-born participants were acculturated to aspects of the mainstream Swedish lifestyle, including dietary practices $^{(75)}$. As recent critiques have shown, acculturation is a multidimensional process that reflects migration type (e.g. economic $v$. asylum-seeking migration), the structures and values of the receiving society, the ethnic identification, values and practices of migrant groups, and the varying degrees of social inclusion and exclusion migrants encounter $^{(76)}$. Since acculturation is a non-linear process, the study did not assume a participant's extent of acculturation based on demographic variables (e.g. years of residence in Sweden) and the analysis, therefore, did not aim to provide a subgrouping of non-Swedish-born participants based on extent of acculturation.

\section{Future research}

The findings suggest that additional research is needed to elucidate the reasons underlying the use of pressuring and restrictive practices by mothers of migrant backgrounds. Although recent research has identified parental resilience to stress ${ }^{(67)}$ and parental socio-economic status ${ }^{(45)}$ as associated with feeding practices, it is also possible that child feeding practices are embedded in broader foodrelated practices ${ }^{(11)}$. Feeding practices are related to the preservation of cultural, communal and familial identities in the context of migration ${ }^{(77,78)}$, and it is still unknown how migration influences child weight status and parental concern about child weight. Differences within the relatively large groups of European-born and non-Europeanborn mothers need to be explored further. Similarly, analysis by migration type (e.g. economic migration $v$. asylum seeking) would allow for a more nuanced understanding of associations between diverging processes of migration - upon the trauma and stress they involve - and parental feeding practices. Finally, future research should examine associations between parental migration and additional feeding practices, particularly encouragement and role modelling ${ }^{(79)}$.

\section{Conclusion}

Differences in controlling feeding practices between Swedish-born and non-Swedish-born mothers were 
identified in a large sample of mothers of diverse countries of birth. Swedish-born and Nordic/Western European-born mothers were less likely to report using pressuring or restrictive feeding practices - practices that may promote unhealthy eating behaviours among children. Child weight and maternal concern about child weight were important confounding variables, especially for restriction. The study highlights the importance of national and migration background in influencing parental feeding practices. Future research should examine the processes that underlie differences between Swedish-born and non-Swedish-born mothers' feeding practices. This could inform the development of inclusive interventions for promoting healthy feeding and eating practices in diverse societies, with sensitivity to the values and experiences of migrant parents, and an understanding of the hardships and structural barriers they encounter throughout the migration process.

\section{Acknowledgements}

Acknowledgements: The authors thank all the participating mothers, Anne Normann from the Childhood Obesity Unit in Malmö, students from Uppsala University (Eva Pettersson, Lisa Lundberg, Sandra Davidsson, Angelica Uhlander) who helped with data collection and data entry, and John Barthelemy from Skåne University Hospital who helped with data entry. Financial support: This work was supported from funds to P.N. by VINNOVA Marie Curie International Qualification (grant number 2011-03443), the Swedish Research Council, Swedish Society of Medicine, Swedish Saving Bank, Nestlé, Kellogg's, Karolinska Institutet, Jerring Foundation, Samariten Foundation, Magnus Bergvall Foundation, Fredrik and Ingrid Thurings Foundation, Helge Ax:son Johnsson Foundation, ishizu Matsumuraîs Donation, Foundation Frimurare Barnhuset in Stockholm, Foundation Barnavård and Crown Princess Lovisa Foundation for Pediatric Care. The funding sources had no role in the study design, collection, analysis or interpretation of the data, writing of the manuscript, or the decision to submit the paper for publication. Conflict of interest: None. Authorship: P.N. conceived the study, designed the statistical approach together with M.S., and supervised the coordination of the study and manuscript process. M.S. performed the statistical analyses and drafted the initial manuscript. K.E. interpreted data and edited the manuscript. A.E., L.L., J.N., C.M., A.P., C.-E.F., K.S. and M.S.F. made a substantial contribution to conception and design, data collection and interpretation of data. All authors contributed to reviewing and approving the final manuscript. Ethics of human subject participation: This study was conducted according to the guidelines laid down in the Declaration of Helsinki and all procedures involving human subjects/patients were approved by the Regional Ethical Board in Lund (approval number 2009/ 362) and by the Regional Ethical Board in Stockholm (approval numbers 2011/1329-31/4, 2012/1104-32, 2012/ 2005-32, 2013/486-32 and 2013/1628-31/2). Written informed consent was obtained from all subjects/patients.

\section{References}

1. Farpour-Lambert NJ, Baker JL, Hassapidou M et al. (2015) Childhood obesity is a chronic disease demanding specific health care - a position statement from the Childhood Obesity Task Force (COTF) of the European Association for the Study of Obesity (EASO). Obes Facts $\mathbf{8}, 342-349$.

2. Ng M, Fleming T, Robinson $\mathrm{M}$ et al. (2014) Global, regional, and national prevalence of overweight and obesity in children and adults during 1980-2013: a systematic analysis for the Global Burden of Disease Study 2013. Lancet 384, 766-781.

3. Lobstein T, Jackson-Leach R, Moodie ML et al. (2015) Child and adolescent obesity: part of a bigger picture. Lancet $\mathbf{3 8 5}$, 2510-2520.

4. Craigie AM, Lake AA, Kelly SA et al. (2011) Tracking of obesity-related behaviours from childhood to adulthood: a systematic review. Maturitas 70, 266-284.

5. Mattes R \& Foster GD (2014) Food environment and obesity. Obesity (Silver Spring) 22, 2459-2461.

6. Biro FM \& Wien M (2010) Childhood obesity and adult morbidities. Am J Clin Nutr 91, issue 5, 1499S-1505S.

7. Ventura AK \& Birch LL (2008) Does parenting affect children's eating and weight status? Int J Behav Nutr Phys Act 5, 15.

8. de Lauzon-Guillain B, Oliveira A, Charles MA et al. (2012) A review of methods to assess parental feeding practices and preschool children's eating behavior: the need for further development of tools. J Acad Nutr Diet 112, 1578-1602, 1602.e1-8.

9. Hartman MA, Hosper K \& Stronks K (2011) Targeting physical activity and nutrition interventions towards mothers with young children: a review on components that contribute to attendance and effectiveness. Public Health Nutr 14, 1364-1381.

10. Power TG (2013) Parenting dimensions and styles: a brief history and recommendations for future research. Child Obes 9, Suppl., S14-S21.

11. Birch LL \& Davison KK (2001) Family environmental factors influencing the developing behavioral controls of food intake and childhood overweight. Pediatr Clin North Am 48, 893-907.

12. Rokholm B, Baker JL \& Sorensen TI (2010) The levelling off of the obesity epidemic since the year 1999 - a review of evidence and perspectives. Obes Rev 11, 835-846.

13. Sundblom E, Petzold M, Rasmussen F et al. (2008) Childhood overweight and obesity prevalences levelling off in Stockholm but socioeconomic differences persist. Int J Obes (Lond) 32, 1525-1530.

14. Sjoberg A, Moraeus L, Yngve A et al. (2011) Overweight and obesity in a representative sample of schoolchildren exploring the urban-rural gradient in Sweden. Obes Rev 12, 305-314.

15. Besharat Pour M, Bergstrom A, Bottai M et al. (2014) Effect of parental migration background on childhood nutrition, physical activity, and body mass index. J Obes $\mathbf{2 0 1 4}$, 406529.

16. Khanolkar AR, Sovio U, Bartlett JW et al. (2013) Socioeconomic and early-life factors and risk of being overweight or obese in children of Swedish- and foreign-born parents. Pediatr Res 74, 356-363.

17. Birch LL, Fisher JO, Grimm-Thomas K et al. (2001) Confirmatory factor analysis of the Child Feeding Questionnaire: 
a measure of parental attitudes, beliefs and practices about child feeding and obesity proneness. Appetite 36, 201-210.

18. Musher-Eizenman DR \& Kiefner A (2013) Food parenting: a selective review of current measurement and an empirical examination to inform future measurement. Child Obes $\mathbf{9}$, Suppl., S32-S39.

19. Birch LL, Fisher JO \& Davison KK (2003) Learning to overeat: maternal use of restrictive feeding practices promotes girls' eating in the absence of hunger. Am J Clin Nutr 78, 215-220.

20. Fisher JO \& Birch LL (2002) Eating in the absence of hunger and overweight in girls from 5 to $7 \mathrm{y}$ of age. Am J Clin Nutr 76, 226-231.

21. Francis LA \& Birch LL (2005) Maternal weight status modulates the effects of restriction on daughters' eating and weight. Int J Obes (Lond) 29, 942-949.

22. Jansen PW, Roza SJ, Jaddoe VW et al. (2012) Children's eating behavior, feeding practices of parents and weight problems in early childhood: results from the populationbased Generation R study. Int J Behav Nutr Phys Act 9, 130.

23. Rollins BY, Loken E, Savage JS et al. (2014) Maternal controlling feeding practices and girls' inhibitory control interact to predict changes in BMI and eating in the absence of hunger from 5 to 7 y. Am J Clin Nutr 99, 249-257.

24. Galloway AT, Fiorito L, Lee Y et al. (2005) Parental pressure, dietary patterns, and weight status among girls who are 'picky eaters'. J Am Diet Assoc 105, 541-548.

25. Gregory JE, Paxton SJ \& Brozovic AM (2010) Pressure to eat and restriction are associated with child eating behaviours and maternal concern about child weight, but not child body mass index, in 2- to 4-year-old children. Appetite $\mathbf{5 4}$ 550-556.

26. Galloway AT, Fiorito LM, Francis LA et al. (2006) 'Finish your soup': counterproductive effects of pressuring children to eat on intake and affect. Appetite 46, 318-323.

27. Rodgers RF, Paxton SJ, Massey R et al. (2013) Maternal feeding practices predict weight gain and obesogenic eating behaviors in young children: a prospective study. Int $J$ Behav Nutr Phys Act 10, 24

28. Faith MS, Berkowitz RI, Stallings VA et al. (2004) Parental feeding attitudes and styles and child body mass index: prospective analysis of a gene-environment interaction. Pediatrics 114, e429-e436.

29. Birch LL \& Fisher JO (2000) Mothers' child-feeding practices influence daughters' eating and weight. Am J Clin Nutr $\mathbf{7 1}$, 1054-1061.

30. Farrow CV \& Blissett J (2008) Controlling feeding practices: cause or consequence of early child weight? Pediatrics $\mathbf{1 2 1}$, e164-e169.

31. Farrow C, Blissett J \& Haycraft E (2011) Does child weight influence how mothers report their feeding practices? Int $J$ Pediatr Obes 6, 306-313.

32. Hurley KM, Cross MB \& Hughes SO (2011) A systematic review of responsive feeding and child obesity in highincome countries. J Nutr 141, 495-501.

33. Rhee KE, Coleman SM, Appugliese DP et al. (2009) Maternal feeding practices become more controlling after and not before excessive rates of weight gain. Obesity (Silver Spring) 17, 1724-1729.

34. Afonso L, Lopes C, Severo M et al. (2016) Bidirectional association between parental child-feeding practices and body mass index at 4 and 7 y of age. Am J Clin Nutr $\mathbf{1 0 3}$, 861-867.

35. Ek A, Sorjonen K, Eli K et al. (2016) Associations between parental concerns about preschoolers' weight and eating and parental feeding practices: results from analyses of the Child Eating Behavior Questionnaire, the Child Feeding Questionnaire, and the Lifestyle Behavior Checklist. PLoS One 11, e0147257.
36. Jansen PW, Tharner A, van der Ende J et al. (2014) Feeding practices and child weight: is the association bidirectional in preschool children? Am J Clin Nutr 100, 1329-1336.

37. Webber L, Cooke L, Hill C et al. (2010) Child adiposity and maternal feeding practices: a longitudinal analysis. $A m \mathrm{~J}$ Clin Nutr 92, 1423-1428.

38. May AL, Donohue M, Scanlon KS et al. (2007) Child-feeding strategies are associated with maternal concern about children becoming overweight, but not children's weight status. J Am Diet Assoc 107, 1167-1175.

39. McPhie S, Skouteris H, Daniels L et al. (2014) Maternal correlates of maternal child feeding practices: a systematic review. Matern Child Nutr 10, 18-43.

40. Bornstein MH (2012) Cultural approaches to parenting. Parent Sci Pract 12, 212-221.

41. Patrick H, Hennessy E, McSpadden K et al. (2013) Parenting styles and practices in children's obesogenic behaviors: scientific gaps and future research directions. Child Obes $\mathbf{9}$, Suppl., S73-S86.

42. Regber S, Novak M, Eiben G et al. (2013) Parental perceptions of and concerns about child's body weight in eight European countries - the IDEFICS study. Pediatr Obes $\mathbf{8}$, 118-129.

43. Sjoberg A, Lissner L, Albertsson-Wikland K et al. (2008) Recent anthropometric trends among Swedish school children: evidence for decreasing prevalence of overweight in girls. Acta Paediatr 97, 118-123.

44. Kaufman L \& Karpati A (2007) Understanding the sociocultural roots of childhood obesity: food practices among Latino families of Bushwick, Brooklyn. Soc Sci Med 64 , 2177-2188.

45. Cardel M, Willig AL, Dulin-Keita A et al. (2012) Parental feeding practices and socioeconomic status are associated with child adiposity in a multi-ethnic sample of children. Appetite 58, 347-353.

46. Cachelin FM \& Thompson D (2013) Predictors of maternal child-feeding practices in an ethnically diverse sample and the relationship to child obesity. Obesity (Silver Spring) 21, $1676-1683$.

47. Worobey J, Borrelli A, Espinosa C et al. (2013) Feeding practices of mothers from varied income and racial/ ethnic groups. Early Child Dev Care 183, 1661-1668.

48. Wehrly SE, Bonilla C, Perez M et al. (2014) Controlling parental feeding practices and child body composition in ethnically and economically diverse preschool children. Appetite 73, 163-171.

49. Blissett J \& Bennett C (2013) Cultural differences in parental feeding practices and children's eating behaviours and their relationships with child BMI: a comparison of black AfroCaribbean, white British and white German samples. Eur J Clin Nutr 67, 180-184.

50. Nowicka P, Sorjonen K, Pietrobelli A et al. (2014) Parental feeding practices and associations with child weight status: Swedish validation of the Child Feeding Questionnaire finds parents of 4-year-olds less restrictive. Appetite 81, 232-241.

51. Ek A, Sorjonen K, Nyman J et al. (2015) Child behaviors associated with childhood obesity and parents' self-efficacy to handle them: confirmatory factor analysis of the Lifestyle Behavior Checklist. Int J Behav Nutr Phys Act 12, 36.

52. Ek A, Chamberlain Lewis K, Ejderhamn J et al. (2015) The More and Less study: a randomized controlled trial testing different approaches to treat obesity in preschoolers. $B M C$ Public Health 15, 735 .

53. Cole TJ, Bellizzi MC, Flegal KM et al. (2000) Establishing a standard definition for child overweight and obesity worldwide: international survey. BMJ 320, 1240-1243.

54. Hedenbro M, Shapiro AF \& Gottman JM (2006) Play with me at my speed: describing differences in the tempo of parentinfant interactions in the Lausanne Triadic Play paradigm in two cultures. Fam Process 45, 485-498. 
55. Powers SW, Chamberlin LA, van Schaick KB et al. (2006) Maternal feeding strategies, child eating behaviors, and child BMI in low-income African-American preschoolers. Obesity (Silver Spring) 14, 2026-2033.

56. Robinson TN, Kiernan M, Matheson DM et al. (2001) Is parental control over children's eating associated with childhood obesity? Results from a population-based sample of third graders. Obes Res $\mathbf{9}, 306-312$.

57. Gemmill AW, Worotniuk T, Holt CJ et al. (2013) Maternal psychological factors and controlled child feeding practices in relation to child body mass index. Child Obes 9, 326-337.

58. Shankardass K, McConnell R, Jerrett M et al. (2014) Parental stress increases body mass index trajectory in preadolescents. Pediatr Obes 9, 435-442.

59. El-Behadli AF, Sharp C, Hughes SO et al. (2015) Maternal depression, stress and feeding styles: towards a framework for theory and research in child obesity. Br J Nutr 113, Suppl., S55-S71.

60. Mitchell S, Brennan L, Hayes L et al. (2009) Maternal psychosocial predictors of controlling parental feeding styles and practices. Appetite 53, 384-389.

61. Haycraft E, Farrow C \& Blissett J (2013) Maternal symptoms of depression are related to observations of controlling feeding practices in mothers of young children. $J$ Fam Psychol 27, 159-164.

62. Goulding AN, Rosenblum KL, Miller AL et al. (2014) Associations between maternal depressive symptoms and child feeding practices in a cross-sectional study of low-income mothers and their young children. Int J Behav Nutr Phys Act 11, 75.

63. Hurley KM, Black MM, Papas MA et al. (2008) Maternal symptoms of stress, depression, and anxiety are related to nonresponsive feeding styles in a statewide sample of WIC participants. J Nutr 138, 799-805.

64. National Collaborating Centre for Mental Health (2010) Depression: The Treatment and Management of Depression in Adults (Updated Edition). NICE Clinical Guidelines no. 90. Leicester: British Psychological Society.

65. Ornelas IJ \& Perreira KM (2011) The role of migration in the development of depressive symptoms among Latino immigrant parents in the USA. Soc Sci Med 73, 1169-1177.

66. Arbona C, Olvera N, Rodriguez N et al. (2010) Acculturative stress among documented and undocumented Latino immigrants in the united states. Hisp J Behav Sci 32, 362-384.

67. Eli K, Sorjonen K, Mokoena L et al. (2016) Associations between maternal sense of coherence and controlling feeding practices: the importance of resilience and support in families of preschoolers. Appetite 105, 134-143.

68. Offer A, Pechey R \& Ulijaszek S (2010) Obesity under affluence varies by welfare regimes: the effect of fast food, insecurity, and inequality. Econ Hum Biol 8, 297-308.

69. Brewis AA, Wutich A, Falletta-Cowden A et al. (2011) Body norms and fat stigma in global perspectives. Curr Anthropol 52, 269-276.

70. Statistics Sweden (2012) Home page. http://www.sbc.se (accessed November 2012).

71. Johnson WD, Bouchard C, Newton RL Jr et al. (2009) Ethnic differences in self-reported and measured obesity. Obesity (Silver Spring) 17, 571-577.

72. Wen M \& Kowaleski-Jones L (2012) Sex and ethnic differences in validity of self-reported adult height, weight and body mass index. Ethn Dis 22, 72-78.

73. Himes JH (2009) Challenges of accurately measuring and using BMI and other indicators of obesity in children. Pediatrics 124, Suppl. 1, S3-S22.

74. Huybrechts I, Himes JH, Ottevaere C et al. (2011) Validity of parent-reported weight and height of preschool children measured at home or estimated without home measurement: a validation study. BMC Pediatr 11, 63.

75. Satia-Abouta J, Patterson RE, Neuhouser ML et al. (2002) Dietary acculturation: applications to nutrition research and dietetics. J Am Diet Assoc 102, 1105-1118.

76. Schwartz SJ, Unger JB, Zamboanga BL et al. (2010) Rethinking the concept of acculturation: implications for theory and research. Am Psychol 65, 237-251.

77. Sukovic M, Sharf BF, Sharkey JR et al. (2011) Seasoning for the soul: empowerment through food preparation among Mexican women in the Texas colonias. Food Foodways 19, 228-247.

78. Rabikowska M (2010) The ritualisation of food, home and national identity among Polish migrants in London. Soc Identities 16, 377-398.

79. Gevers DW, Kremers SP, de Vries NK et al. (2014) Clarifying concepts of food parenting practices. A Delphi study with an application to snacking behavior. Appetite 79, 51-57. 